\title{
NOVEL MODEL FOR RURAL HOUSING DEVELOPMENT
}

\author{
Aravind Kumar R ${ }^{1}$, Arvind Vasudevan ${ }^{2}$, Annapurna Ayyappan ${ }^{3}$, Aman Gaur ${ }^{4}$ \\ ${ }^{I}$ B.Tech Student, Department of Telecommunication Engineering, SRM University, Chennai \\ ${ }^{2}$ B.Tech Student, Department of Electrical and Electronics, SRM University, Chennai, India \\ ${ }^{3}$ B.Tech Student, Department of Telecommunication Engineering, SRM University, Chennai, India \\ ${ }^{4}$ B.Tech Student, Department of Civil Engineering, Vellore Institute of Technology, Vellore, India
}

\begin{abstract}
It was once said, that a man travels the world over in search of what he needs and returns home to find it. It underlines the basic need for every individual to have a roof above his head. The Indian growth story has caught the imagination of the entire world, as a sleeping giant awakens from its slumber. But the ground reality in the $9^{\text {th }}$ richest country of the world, paints a different picture. $70 \%$ of the country's population lives in rural villages, and there are 78 million homeless people despite the country's growing economic stature. It becomes the duty of the nation to provide affordable and practical housing to its most important resource, its human capital. The main aim of this paper is to investigate on process and materials that provide affordable, efficient housing to the homeless of the country. It explores the possibilities of using low-cost substitutes to conventional building materials. It further attempts to enhance the living conditions in rural regions by developing alternate methods of generating electricity, smart roof structure to provide ambient light and a comprehensive business model to carry out implementation of such a project on a large scale. The housing technique discussed by this paper addresses the above issues by putting forward a blueprint for building a cleaner, brighter and prosperous tomorrow.
\end{abstract}

Keywords: Rural, Rural Housing, Smart Roof, and Alternate materials

\section{INTRODUCTION}

The Indian growth story has caught the imagination of the entire world, as a sleeping giant awakens from its slumber. But the ground reality in the $9^{\text {th }}$ richest country of the world, paints a different picture. $70 \%$ of the country's population lives in rural villages, and there are 78 million homeless people despite the country's growing economic stature. It becomes the duty of the nation to provide affordable and practical housing to its most important resource, its human capital. Traditional methods of house building are rife in interior villages around the country with mud and thatch houses a common sight. But these represent a temporary solution, prone to the elements and unstable in construction. Sadly, modern building techniques represent an unaffordable luxury for the vast majority of the rural populace, thus creating a vicious cycle. Added to the same, a large number of villages lack basic electricity access and still rely on antiquated kerosene lamps to provide them with light.

This project proposes an innovative method of constructing houses that are cost effective and stable. Using bricks of plastic glass as its primary building block, the houses are stronger, cheaper and more stable than even standard houses. Added to that, by harnessing the Tyndall effect, the transparent roof can provide lighting to those inside during the day that would enable them to carry out their activities without subjecting themselves to the noxious fumes of kerosene lamps. A Photovoltaic element charges a battery that powers an LED, which accounts for lighting inside the houses during the night. In this manner, the problems that plague the homeless of the country could be alleviated and every Indian could eventually afford a roof above his head.

\section{NEEDS BEING MET}

Food, clothing and shelter are the three fundamental necessities that man needs to survive in the world. Over the years, many organizations have launched pilot programs aiming to accelerate rural development, with varying degrees of success. Ideally, around 70\% of the country's population that lives in rural regions should be enjoying a better quality of life than those stuck in the quagmire of over-population, pollution and ill-health that our urban centers have become. However, most villagers are in a state of acute deprivation due to the lack of basic amenities. The most basic of these is a roof above one's head. Thus, there is a pressing need to provide cheaper, quality housing to the vast villages of our country. In a country where 90 million people live below the global poverty standard of 1 \$ per day, this project would help create housing that the government is capable of constructing with the least cost possible. According to the National Family Health Survey, concluded in 2000 by the Indian government, only $19 \%$ of the rural population lives in pucca (strong) houses, while the remaining live in kaccha (weak) and semi-pucca houses with mud walls and thatched roofs.

Without the security and comfort of a home, there is no escaping the difficulties resulting from poverty. Poor people do not have the financial means to buy or construct houses with their savings, and therefore they live in their ancestral huts, those rented from landlords (with ensuing obligations), or government-supplied houses. Most of the huts and 
shelters that villagers build consist of clay, hay, cow dung and grains. Thatched roofs are most common, while leaves, straw and agricultural wastes are used among the other main ingredients for the hutments. But more often than not these "shelters" crumble under the forces of nature, be it heavy rains or fast winds, and are often to be repaired or rebuild. This task represents a waste of the human capital and resources that are available and by providing a permanent shelter; we can help focus the efforts of the people towards more productive tasks. Various factors are responsible for pushing people away from looking for a permanent structure for their house. The most important of these is the high building cost. There is need for a large amount of capital to create a conventional permanent house, which is not available to the majority of villagers. Moreover, this technique of building also helps the government cater to the needs of the vast population that struggles for two square meals every day, for which a house is nothing but a distant dream.

Another major problem that exists is the lack of electricity in most villages. A recent study tells us that more than $43 \%$ of rural household still use kerosene to light their houses because they do not have access to electricity infrastructure. Kerosene, being a primary petroleum product is not very efficient and highly polluting. This causes great environmental and heath damages in villages. The implications of no electrical access are enormous: families forego entrepreneurial endeavors, children cannot study after dark, health clinics do not function properly, and women are burdened with time consuming chores such as pounding grain or hauling water, leaving them with less time to engage in income generating activities. By using non-polluting and self-generating Photovoltaic element, this project aims to bring a ray of light into the lives of the poor.

Keeping the above needs in mind, this project is a humble but sincere effort to put forward a cost effective model of house-building. By using recycled waste as the basic building element and other eco-friendly materials, there is a reduction in the cost and an improvement of structural stability. The roofing system also eliminates the dependency on electricity during the day and offers alternative sources of lighting during the night.

\section{EXISTING SOLUTIONS}

The problem of homelessness has existed for decades, but due to the vastness of the issue there has not been any complete solution. In the US, a major plan titled 'Housing First' was adopted that espoused the importance of providing permanent accommodation rather than temporary relief to the homeless. In the Indian scenario, the problem is more complex. There exist shanties in all major urban and rural areas that are unauthorized buildings with poor materials. Thus people, who can't afford pucca houses, end up on the wrong side of the law, as it is the easiest option available to them. When the administration cracks down on these illegal structures, it leaves the families on the road with nowhere to go. Also, the housing boards of various states provide low cost housing to the poor, by means of random allotment.

Currently, low cost housing in villages involves making modifications to optimum building design while maintaining them within the required safety parameters. There are certain techniques like the Moladi building technique that reduces the cost compared to traditional methods. Also reducing the plinth area and using locally sourced materials as substitutes are popular methods. For example, substituting of burnt bricks with soil cement blocks would reduce the cost of the structure.

Two innovative shelters were built on the bank of the Yamuna River for the homeless by the organization, Micro Home Solutions. These shelters were built from a bamboo frame, with double walls made of canvas to provide an air cavity for insulation. The false ceiling prevented winter dew and was adaptable to provide cooling in the summer. The flooring was laid with bricks, which were raised to prevent rodents and animals from surfacing. The project was successful, but is more suited to serving as a shelter than a permanent low-cost building technique for villages.

The solution closest to meeting the basic housing needs of villagers is the Bamboo House Prototype in Nagpur by Wonder Grass Pvt Limited. Similar to our project providing a lost-cost sustainable alternative to the modern concrete home being offered in India was the driving objective. This project incorporated the properties of bamboo's lightness and flexibility in its many uses. These included splitting to construct wattle and daub construction for wall panels, as well as constructing open web trusses that support the roof, and second story addition if there is a need for one once the family requires more space. Currently six units are completed and they are being tested for their viability.

On the question of rural electrification, various efforts are being concentrated towards improving the reach of electricity in our country. Still of the 300 million people in India with no access to electricity, $87 \%$ are from the rural areas. The installation of standalone solar panels have been mooted and implemented on trial basis in certain regions of the country. These have demonstrated a reasonable degree of success while providing for the basic lamps during dark. An initiative by the company SunEdison, will also see the installation of distributed solar power plants around India, helping the villagers in their quest for a better life.

Another initiative that exists is the Mera Gao Power Grid Program. It has developed a low cost micro grid tailored to the needs of off-grid villages. According to official statements, MGP will construct and operate approximately 40 new village-level micro grid lighting facilities to reach 4,000 new customers and 20,000 new beneficiaries in Sitapur districts of Uttar Pradesh, India. However, this plan is still in the implementation stage and the overall success of the program remains to be seen. 
The closest solution in this regard is the power generation system in Bihar using Rice husk. The system heats up the rice husk and uses the clean-burning gases produces to drive an engine. This engine drives a turbine and produces electricity. Initial reports suggest that the company, Husk Power Systems, have done a commendable job.

However, there is no existence of an integrated solution where total infrastructure is provided to the common man in India's villages. Most of these initiatives have not yet demonstrated their capacity to make a quantum leap in their reach, providing both housing and electricity to a large population. Thus, our project aims to take a holistic approach to the needs of the villagers and attempts to create a single structure capable of solving both problems.

\section{PROPOSED IDEA AND THEIR NOVELTY}

Our model concentrates on building a cost effective residential structure for people, that uses plastic sand, sand bricks and other waste materials that are easily available and accessible to people. The design is flexible and can be modified to cater to the needs of constructing schools, meeting halls and other structures. Further, efforts have been made to provide abundant natural lighting during the day, thereby reducing dependency on electricity, and to provide alternate sources of energy to locally generate electricity for the residents.

The model uses plastic sand bricks as its primary building material. It can be made locally by melting waste plastic and filtering the molten plastic into a container of water. These droplets of plastic will form sand-like particles after drying thus giving them the name, plastic sand. Plastic sand cannot be used as a standalone constructing material since it does not possess the requisite strength that is required for constructing purposes. Hence it is mixed with sand in a suitable ratio to create an enhanced product that satisfies our requirements. The resultant material is plastic sand brick which is two times stronger and $30 \%$ lighter than conventional concrete bricks. The plastic sand bricks are resistant to oils, acids, alkalis, salt and also display a degree of imperviousness to heat. The subsequent challenge was to ascertain which binder material (like cement in conventional buildings) had good tensile strength to hold the bricks together. An alternative to cement was looked into since the cost-factor was the primary concern. Further investigation led to the testing of thermocol glue as a possible material. Thermocol glues are very interesting binder substitutes and are prepared by dissolving thermocol in acetone, giving them very good tensile strength. The unique selling point of thermocol glue lies in the fact that it can be easily prepared and used as per the requirement, further lowering the cost. Thus, the low cost and availability, added to its inherent water-resistant properties and insulation against temperature makes it ideal for use as binders.

Thus, the amount of concrete used in the building of the houses is greatly limited, making for a cheaper and more streamlines process. The conventional methods of homebuilding can be easily adapted to include the above thus preventing the need for specialized workers for these houses. Also, the project gives an impetus to recycling efforts by using a raw material that directly derives from waste plastic.

The next challenge that required attention was to help tackle the lighting and electricity crisis that exists in most households of rural India. This problem is more acute in the case of rural schools, where well-lit classrooms are a basic necessity to facilitate good learning. Sadly, most schools in rural India are poorly designed with no facility for natural lighting. Though these Gram Vidyalayas boast of having tube-lights and fans, there is poor or even non-existent electricity supply. Thus the solution that this project looks into, is utilizing the best source of light that mankind has abundantly: The Sun. Thus, the design of the house provides for natural lighting during the daytime.

The obvious idea was to have a translucent roof that is capable of providing ample natural lighting. There was a need to provide roofing material that was solid enough to withstand the rigors of nature, capable of preventing security issues while being translucent enough to let in enough light. Acrylic was an ideal material that satisfies both the mechanical and optical properties that were necessary for the roof. The need for uniform lighting inside the house led to the application of the Tyndall effect to the problem. By containing a colloidal solution between, two $50 \mathrm{~mm}$ thick translucent Acrylic sheet boxes, the Tyndall effect can be harnessed to provide uniform lighting due to the scattering of the incoming sunlight. These colloidal roof blocks are supported by roof grills made of wood. A lean-to-roof structure was also adopted to make the building more stable.

The next important step was to choose an appropriate colloidal solution. The need of the hour was a colloid that had all the requisite optic properties, had enough stability while being easily available to rural villagers. Starch solution was selected as the most suitable colloidal solution due to its high stability and easy availability.

Though the above system provides for a stable shelter with good lighting during the day, there is a need for an alternative once the sun sets. There is a need to provide provisions to harness heat and store the same as electricity during the day, so it can provide lighting during the night. A thermoelectric generator like a simple solar panel does this task, and completes the cycle of lighting.

Thus with all these individual components working in harmony, the model is capable of accomplishing the aims that it set out to. It provides cheaper, stronger shelter structures that provide ample lighting during the day and night. This would be of special use to rural schools, where children could be encouraged to study and work in a better environment. The reduced dependence on the electricity grid in this model will also ensure significant economic saving, that could be used instead to provide greater comforts to all. 
The structures, built out of plastic sand are also more stable than concrete structures; protect people better in times of disaster and heavy rain. The house has been designed by implementing a smart roof design that harnesses the principle of Tyndall effect shown by colloidal solutions, to provide free and abundant lighting during the day. The Photovoltaic elements harness the energy of the Sun, to provide electricity during the night. Thus the project hopes to light the lives of people living in the darkness of poverty in our villages.

\section{FEASIBILITY AND IMPLEMENTATION}

The following feasibility study briefly illustrates how the proposed project can be implemented at the village level. In order to understand the potential pitfalls in implementing any project, we had to do extensive research on the projects that had preceded our project. We came across several challenges that these projects had to face when it came to actual implementation of the project at the rural level.

The following points succinctly describe the lessons we learned during the research phase:

a) The technology should be appropriate and obtainable to rural areas since replacement parts are difficult to obtain.

b) Villagers should also take responsibility for maintaining the technology.

c) Villagers should also be given a monetary stake in the project. Because, only then will they exhibit accountability towards maintenance, and become financially stable.

d) There are insufficient financial services for projects that involve lighting and sustainable structural products acquisition in rural areas, as there is a high risk factor. This opens up market opportunities for MFIs (Micro Finance Institutions) as they can bridge the gap between need and service availability.

e) When projects come with a guarantee of stability and continuous availability, then people are willing to pay more initially since they actually save more when the maintenance and replacement costs are cut down in the long run.

f) Many of these benefits are very important to women and children since most of them are confined to structural premises like homes, schools etc. and can use the lighting and stable structure, to engage in additional income generating activities.

g) The dual benefit of light and stable structure emphasizes two major advantages: enterprise and education.

Thus keeping this in mind, the feasibility of the project was studied in the following terms:

\subsection{Technology}

\subsubsection{Superstructure}

Currently, the homes in rural villages are made of readily available materials like hay, straw, mud, cow dung and sometimes brick. The roofs are made of woven straw or bamboo, with grains and thatched hay. The walls are not sealed at the wall intersections and thus, the structure is not only weak but it also provides inadequate protection against small wild animals which enter the premises. These structures are also inflammable.

As these are in no way permanent, the villagers have to frequently rebuild and improve the structural capability of their homes, a costly and time consuming endeavor.

The solution is quite simple, involving the use of plastic sand bricks for construction. The ingredients of plastic sand are plastic sand and sand. The plastic sand is obtained by melting waste plastic and passing the melted plastic through a filter to obtain plastic granules. Plastic is readily available, as it is a major constituent of urban garbage. The other ingredients of plastic sand bricks are easily available too. When these ingredients are mixed proportionately and sun dried or fired, they form very strong bricks which can be used for constructing a house. After the brick has hardened, it provides the following characteristics:

a) Resistant to oils, acids, alkalis and salt

b) Water resistant

c) $30 \%$ lighter than concrete

d) Does not expand much in heat

e) Insulates against heat and cold

f) Flame resistant

g) Recyclable

h) Can be drilled, drawn through, welded and glued

Also, these bricks are only half the price of concrete. Additionally, a material called thermocol glue can also be used as an adhesive. The glue can be prepared easily by dissolving equal weight of waste thermocol in equal weight of acetone. It has the properties of high tensile strength, ability to stick bricks, longer shelf life and smooth consistency and is cheaper than commercial adhesives.

\subsubsection{Smart Roof}

The smart roof will be made of plastic sand bricks too. However, we will be introducing waste plastic box in order to hold the colloid and then fit this unit into the roof structure at a specific location. This position will be chosen on the roof in such a way, that maximum illumination takes place within the house when sunlight penetrates through the colloid and displays the Tyndall effect. This occurs during day time.

The colloid prepared by us consists of 200 cubic $\mathrm{cm}$. of hot water, 500 cubic $\mathrm{cm}$. of plain water and a table spoon of starch powder.

\subsubsection{Thermo-Electric Energy}

The structure will be complete with a thermoelectric system that will capture the sunlight and save the energy in batteries for further use. The most common in this respect will be solar cells that convert sunlight to electricity and store it in batteries for use during the night time. 


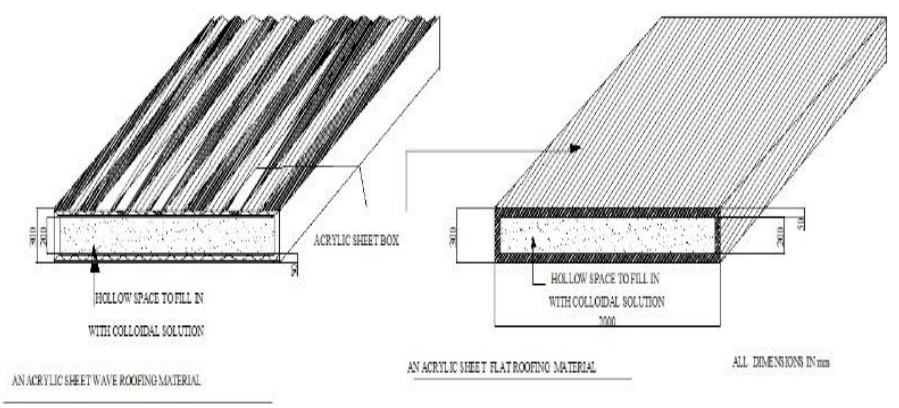

Fig -1: Roof Material Design

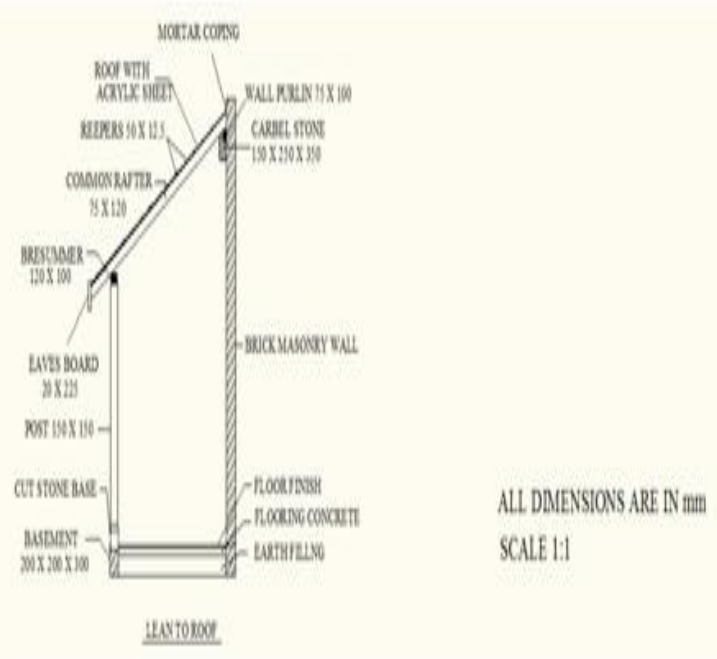

Fig -2: Lean to roof configuration

\subsection{Engineering and Economic Parameter}

1) The following parameters are significant for the implementation of the project:

a) Capital costs: these include all the initial costs for purchasing and setting up an operating system.

b) Ongoing costs: Ongoing costs are a measure of any costs associated with the maintenance or usage of the technology. These costs include any parts and any labor costs required to keep a system operational. In some cases, the money transacted for these costs remain within the village as in the case of employing a local technician to maintain a system, but in other cases, the money will leave the village entirely.

c) Productivity: productivity is essentially the amount of light the colloid box can emit and the energy available from the thermo-electric system. It also deals with the reduced investment and time in rebuilding the house over a period of time.

d) Mobility: a product can be either moveable or not. Here, the product, the house is not moveable.

e) Safety: this project will surely ensure safety from the forces of nature, wild animals and predators entering the house and fire.

f) Social acceptance: if the technology is fairly simple to understand and familiar, the villagers will easily adopt the technology which will reduce the pilot project period and also increases the success rate of the project village wide.

g) Year-round use: this depends on the strength of the bricks and how it bears the load subject to different conditions. It is also influenced by the extent to which the technology can be adapted to run from alternate power sources during the monsoon period when solar irradiance is lower.

2) The following factors play an important role in deciding the feasibility of any project.

a) Village population: the population of the village determines the level of anonymity between villagers. If the village is densely populated, then the villagers may not know a lot of villagers

b) Population age distribution: population age distribution determines how transitory a population is. A greater transition is possible with higher concentration of working adults as compared to children and the elderly.

c) Population caste and religious distribution: these factors will help us to understand the social cohesiveness in a village.

d) Village longevity: this factor tells us for how long the village has been in existence. A longer period indicates poor transitory population.

e) Travel time between village and nearest MFI representative: this factor is indicative of how expensive it will be to monitor the village and any clients within, based on time, travel costs etc.

f) Number of businesses per capita: this factor is important to determine the stability of income and the nature of transition.

g) Number of savings and other financing options: these are proxy for default risk, with more options implying a lower cost to borrowers of lost future financing opportunities in the event of default and therefore a higher risk of default.

Expected time for connection to electricity grid

\subsection{Affordability and Scalability}

Affordability depends upon the per capita income, seed money provided by the local panchayat to the villagers and the various schemes of financial inclusion of MFIs and financial institutions. Also, another method employed will use the microcredit method of lending to the Self Help Groups (SHGs). An example of that would be:

a) The AADHAR scheme

b) FEDERAL BANK has provided financial assistance and training to scores of villagers through its "VILLAGE ADOPTION" programme.

Our financial model, based on similar lines will work towards increasing the affordability of the project.

The project is very scalable. The primary objective of the project is to develop a scalable, financially sustainable business model that a microfinance institution can 
implement in extremely poor rural areas. When implemented, this model will not only allow households to obtain light inside a stable home, but also create a new, viable business in the form of a micro-utility. This strategy also enables a rapid expansion of the income generating and development activities this model will create within the selfhelp groups themselves and the villages they operate in. With greater availability of light, the self-help groups will be able to expand their business activities into the evenings and also to generate income from a new enterprise, the provision of light to their neighbors. With light, villagers will be able to expand their own participation in cottage industries such as craft making, benefiting from the additional income opportunities this presents, as well as the opportunities for non-income generating activities such as education and safety this light will provide.

Once this project has been successfully implemented at the rural level, the technology can be made more affordable by improving the materials used and developing the existing structure in terms of capability and alternate technologies for renewable energy. Last but not the least, this technology can also be extended for making such sustainable buildings even in towns and cities.

\subsection{Implementation Strategy}

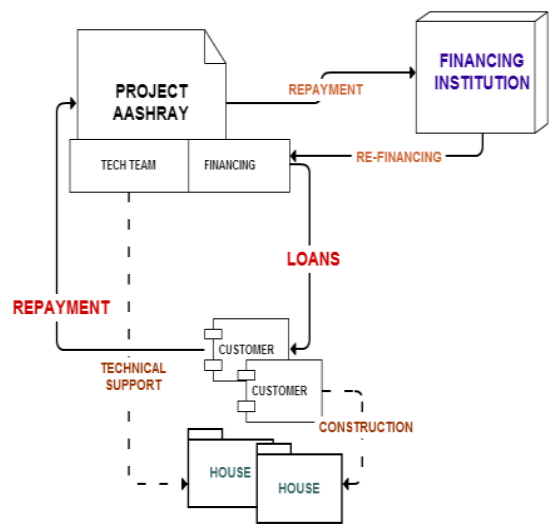

Fig -3: Implementation Flowchart

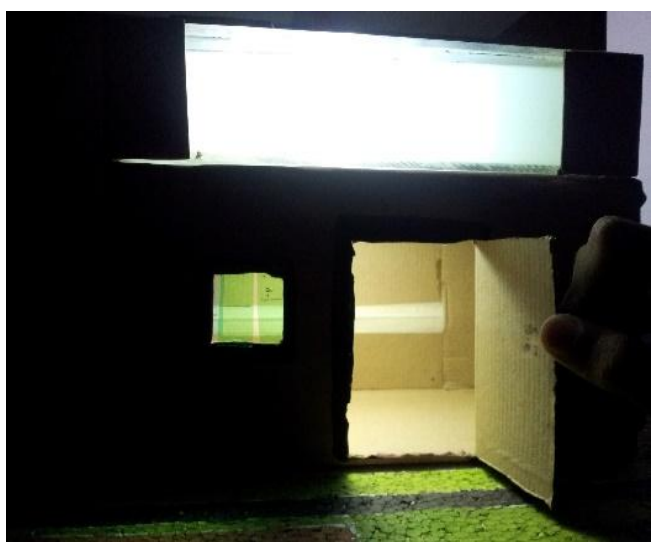

Fig -4: Prototype

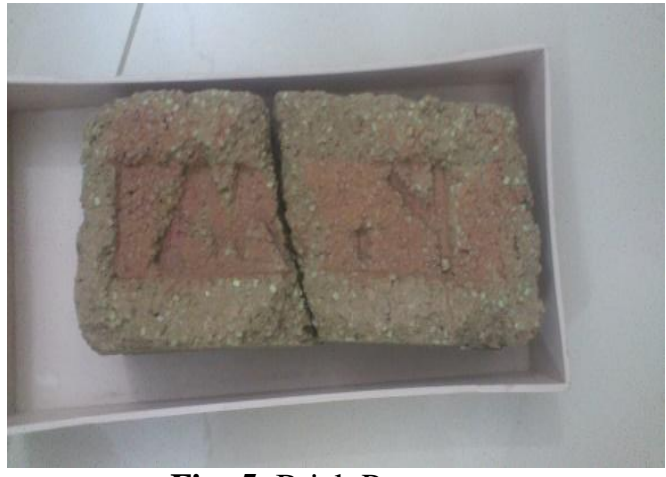

Fig -5: Brick Prototype

\section{IMPACT EVALUATION}

The project has identified the needs of the people in rural India and suggests some innovative measures that can be implemented. However, the true success of this project would lie in finding out why and how this program works. In any given habitable environment, people seek a livelihood wherein effort or work is compensated with appropriate income. Monetary requirements to further their chosen line of work are inevitable, for which credit facilities become essential. Hence, providing credit facilities to the rural people is the first step in ensuring that they get a better livelihood. A micro finance model needs to be in place to ensure that people are provided with enough credit to construct a better shelter for themselves and their family. The Grameen Bank of Bangladesh holds an iconic position in the world of microfinance. It is credited with proving that 'the poor are bankable'. The target group for this project is the 'homeless' of varying degrees, either without a proper roof over their head or those who invest their entire lifesavings to build a 'pucca' house with high cost materials.

In the case studies considered, two broad methods of financing were used for obtaining energy systems: donations or self-financing. However, cases of donated systems are very common in the literature. It is important to note that heavy reliance on NGOs and donor support does not create a sustainable approach for providing electricity to rural communities. Hence there is an immediate requirement for a Micro Finance Institution-like setup. The model that we came up with is based on the lessons learnt from the Grameen Bank of Bangladesh. This financing model has a number of features that include:

a) Lending to poor, rural women(as they are less likely than men to use loans badly and are more reliable in repayment)

b) Organizing women into cells of five, that take collective responsibility for each other's loans (peer screening process)

c) Establishing centers where six cells meet, at a set time each week, to apply for loans and make repayments.

d) Requiring clients to make compulsory micro savings each week (to create financial discipline and generate financial collateral for groups), and to make promises about their social conduct. 
e) Simple, standardized products that required regular, small repayments.

f) The abandonment of joint liability (and the idea of social collateral).

\section{REFERENCES}

[1] Importance and Need for Rural Development Instruments under the CAP: A Survey of Farmers' Attitudes in Marginal Areas of Greece Efthalia Dimara and Dirnitris Skuras.

[2] http://india.gov.in/integrated-novel-developmentrural-areas-and-model-municipal-areas-andhrapradesh.

[3] Rajiv Gandhi Rural Housing Corporation Limited.

[4] Selected Socio Economic Statistics, India 2011

[5] www.leancanvas.com

[6] http://www.iay.nic.in/netiay/home.aspx

[7] Credit-cum-Subsidy Scheme for Rural Housing (CSRH) - Bihar Government.

[8] INDIRAMMA - Integrated Novel Development in Rural Areas and Model Municipal Areas, Andhra Pradesh, India.

[9] Sustainability of rural development projects - Best practices and lessons learned by IFAD in Asia.

[10] the self-help housing development process in rural areas - Housing Assistance Council

[11] http://www.hud.gov/offices/adm/about/admguide/hi story.cfm

[12] http://www.homelesshub.ca/solutions/housingaccommodation-and-supports/housing-first

[13] http://www.hhs.gov/homeless/research/endhomeless ness.html

[14] http://www.rurdev.usda.gov/Reports/usdardCustomerSatisfaction 10-2010.pdf

[15] Rural Development Survey

[16] A Social History of Rural Low-Income Housing Assistance Programs in the "Black Belt" Region of West Alabama Patrick Kennealy.

\section{BIOGRAPHIES}

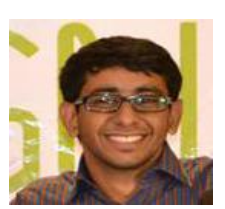

Aravind is currently in his final year majoring in Telecommunication Engineering. He believes in finding simple techno-entrepreneurial solutions to everyday problems

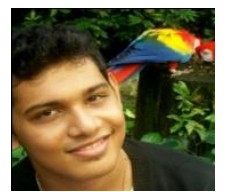

Arvind is an extremely passionate techno geek who aims to deploy alternate energy solutions to rural India. He is currently a final year Electrical Engineering Student.

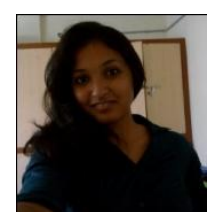

Annapurna is a final year Telecommunication Engineering student who loves solving problems. Business \& technological strategies and implementation is her forte.

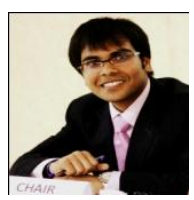

Aman is a final year Civil Engineering student. He is the brain behind structural design and his area of interest is in Construction Engineering and Management. 